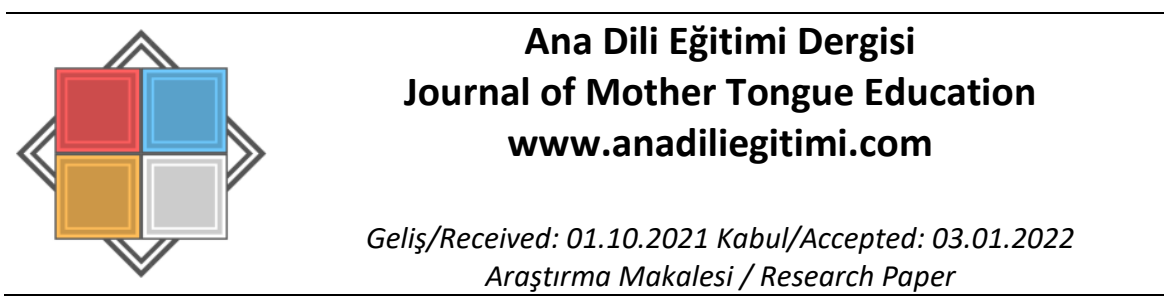

\title{
4+1 Planlı Yazma ve Değerlendirme Modeli Çerçevesinde Gerçekleştirilen Hazırlıkların Yazma Sürecindeki İşlevleri*
}

\author{
Ahmet DEMIREL ${ }^{* *}$ \\ Halit KARATAY ${ }^{* * *}$
}

\begin{abstract}
Öz
Bu araştırmanın amacı 4+1 Planlı Yazma ve Değerlendirme Modeli (PYDM) çerçevesinde gerçekleştirilen hazırlık çalışmalarının yazma sürecindeki işlevlerine ilişkin öğretmen adaylarının deneyimlerini ve algılarını ortaya koymaktır. Bu amaç doğrultusunda araştırma, nitel araştırma desenlerinden olgubilim desenine uygun bir biçimde tasarlanmıştır. Çalışma grubu ölçüt örnekleme yoluyla seçilen otuz öğretmen adayıdır. Araştırmada 4+1 PYDM çerçevesinde hazırlık çalışmaları yapma deneyimine sahip öğretmen adayları çalışma grubu olarak seçilmiştir. Katılımcıların hazırlık çalışmalarının yazma sürecindeki işlevlerine yönelik deneyimlerini ortaya çıkarmak amacı ile yarı yapılandırılmış görüşme formu kullanılarak görüşmeler gerçekleştirilmiştir. Araştırma sonucunda hazırlık aşamasının kendinden sonraki yazma süreçlerinin başarılı bir biçimde gerçekleştirilmesi açısından önemli olduğu görülmüştür. Bununla birlikte hazırlık çalışmalarının belirsizlikleri engelleyerek ve yazarın üretkenliğini artırarak daha nitelikli metinler ortaya çıkarılmasında belirleyici bir rolü olabildiği sonucuna ulaşılmışıı. Ayrıca bu aşamanın yazara konu ile ilgili bilgi ve veri sağlayarak onun yazmaya daha hazır bir hale gelmesini, böylece yazma isteği duymasını ve daha akıı bir şekilde yazmasını sağlayabildiği sonucuna ulaşılmışır.
\end{abstract}

Anahtar Kelimeler: Hazırlık, yazma becerisi, süreç temelli yazma, 4+1 PYDM

\section{The Functions of Preparatory Activities within the framework of the 4+1 Planned Writing and Evaluation Model in the Writing Process}

\begin{abstract}
This study aims to reveal the experiences and perceptions of pre-service teachers regarding the functions of the pre-writing stage carried out within the framework of the 4+1 Planned Writing and Evaluation Model (PWEM) on the writing process. The study is qualitative by design and employed the phenomenology methodology. The study group consists of thirty teacher candidates selected through criterion sampling. Interviews were conducted using a semistructured interview form to reveal the experiences of the participants on the functions of the pre-writing stage in the writing process. The results showed that the pre-writing stage was important for the successful implementation of the writing processes that followed. It was seen that the pre-writing stage could play a decisive role in creating more qualified texts by preventing ambiguities and increasing the productivity of writers. It was also seen that this stage could provide writers with information and data on the topic, enabling them to become prepared to write and increasing both their willingness to write and fluency in writing.
\end{abstract}

Keywords: Pre-writing, writing skill, process-based writing, 4+1 PWEM

\footnotetext{
* Bu çalışma, birinci yazarın “4+1 Planlı Yazma ve Değerlendirme Modelinin Öğretmen Adaylarının Tartışmacı Metin Yazma Becerilerine Etkisi” başlıklı doktora tezinden üretilmiştir.

** Arş. Gör. Dr., Nevşehir Hacı Bektaş Veli Üniversitesi, Eğitim Fakültesi, Türkçe ve Sosyal Bilimler Eğitimi Bölümü, Nevşehir, ahmetdemirel38@hotmail.com, ORCID: orcid.org/0000-0003-2249-565X

*** Prof. Dr., Bolu Abant İzzet Baysal Üniversitesi, Eğitim Fakültesi, Türkçe ve Sosyal Bilimler Eğitimi Bölümü, Bolu, halitkaratay@gmail.com, ORCID: orcid.org/0000-0003-1820-0361
} 


\section{Giriş}

Yazma, yazma sürecini etkileyen unsurların ustaca yönetilmesini gerektiren, hedefe yönelik olarak gerçekleştirilen ve kendi kendini sürdüren bir bilişsel faaliyettir. Yazma başkalarını etkilemek için güçlü bir yol, güçlü bir araçtır (Graham, Gillespie ve McKeown, 2012). Graham (2006) yazmanın farklı amaçlar için gerçekleştirilen bir eylem olduğunu belirtmiş ve yazmayı farklı amaçlara ulaşılması amacıyla başvurulabilecek çok yönlü bir araç olarak tanımlamıştır. Yazma bilgi verme, duygu ve düşünceleri ifade etme, eğlenme gibi birçok farklı amaç için gerçekleştirilen bir faaliyettir. Arıcı ve Ungan (2015) yazmanın kişisel, toplumsal ve uğraşsal bir eylem olduğunu vurgulamış ve yazmanın insanlarla iletişim kurmak için kişisel bir ihtiyaç olduğunu belirtmiştir. Yazmayı konuşma, okuma ve dinlemeden ayıran temel farklarından biri kalıcı olmasıdır. Yüzyıllardır bilgi ve kültürün aktarılmasında kullanılan en temel becerilerden biri yazma becerisidir. Tüm bunlar yazma becerisin insan yaşamında önemli bir yeri olduğunu ve hayatın her alanında ihtiyaç duyulan işlevsel bir beceri olduğunu göstermektedir. Bununla birlikte yazma becerisi en son kazanılan dil becerisi olmakla birlikte aynı zamanda en zor öğrenilen dil becerilerinden biridir. Kişinin eğitim öğretim ortamlarında veya iş ortamında kendisini yazılı olarak iyi bir biçimde ifade edebilmesi önemlidir. Bu nedenle yazma becerisi günümüzde insan hayatının her alanında olduğu gibi okul ve iş hayatında da önemli bir yer tutmaktadır.

Tarihsel olarak Rohman (1965), Emig (1971) ve Murray (1972) tarafından yazma süreçleri ile ilgili yapılan çalışmalar yazmayı süreç olarak ele alan sonraki çalışmalara ışık tutmuştur. Bununla birlikte yazmanın bir süreç olarak ele alınmaya başlanması ve bu süreçlerin araştırılması Flower ve Hayes (1981)'in yazmaya yönelik ortaya koyduğu bilişsel süreç modelinden sonra hız kazanmıştır. Flower ve Hayes (1981) ortaya koyduğu bu bilişsel modelde yazmanın üç temel süreçte meydana geldiğini ileri sürmüştür. Onlara göre yazma; planlama (planning), yazıya aktarma (translating) ve gözden geçirme (reviewing) olmak üzere üç temel süreçten meydana gelmekte ve bu süreçlerin kendi içerisinde alt işlemleri bulunmaktadır. Daha sonraları yazmayı bir süreç olarak ele alan süreç temelli yazma yaklaşımlarında yer alan aşamalar Flower ve Hayes (1981) tarafından ortaya konan bu süreçlerle kısmen farklılık gösterse de temelde bu süreçlerle benzer bir biçimde sunulmuştur (Bayat, 2014; Karatay, 2011).

Seow (2002) yazma sürecini planlama, taslak oluşturma, gözden geçirme ve düzenleme olmak üzere dört aşamada ele alırken Karatay (2011) 4+1 Planlı Yazma ve Değerlendirme Modeli'nde yazma süreçlerini hazırlık, planlama, düzenleme, düzeltme ve paylaşma olarak ele almış ve bu modelin süreç temelli yaklaşımı esas aldığını belirtmiştir. Nabhan (2019) ise yazmanın aşamalarını ön yazı, planlama ve organizasyon, taslak hazırlama, yansıtma, akran/öğretmen değerlendirmesi, düzeltme, son okuma ve yayına hazırlama olarak ele almıştır. Görüldüğü gibi süreç temelli yazma yaklaşımında yazma süreçlerinin ele alınışları ufak farklılıklar göstermekle birlikte temelde benzerlik taşımaktadır. Bu yönüyle süreç temelli yazma temelde yazmanın belirli başlı süreçleri ile birlikte ele alınarak değerlendirilmesini benimseyen bir yaklaşımdır. Süreç temelli yazma yaklaşımı içerisinde yazma süreçlerini, süreçlerin birbiri ile ilişkisini ele alış biçiminden kaynaklı yukarıda da bahsedilen farklılıklardan hareketle farklı yazma öğretim ve değerlendirme uygulamaları ve önerileri ortaya çıkmıştır.

Süreç temelli yazma yaklaşımını benimseyerek yazma süreçlerini ele alan hemen hemen bütün çalışmalarda yazma öncesinde hazırlık, planlama gibi süreçlerin benimsendiği söylenebilir. Bu süreçler kimi kaynaklarda da ön yazma (pre-writing) olarak ele alınmaktadır (Rohman, 1965; Tompkins, 2005; Mogahed, 2013). Yazma öncesinde gerçekleştirilen bu süreçlerin yazma performansı (Baaijen, Galbraith ve de Glopper, 2014) ve ortaya konan yazılı ürünler (Brodney, Reeves ve Kazelskis, 1999) üzerinde etkili olduğu ifade edilmiştir. Mogahed (2013) özellikle genç yazarların yazmaya başlarken ve yazarken sıkıntı çektiklerini bu nedenle yazma öncesi gerçekleştirilen aktivitelerin önemli olduğunu belirtmiştir. Murray (1982) yazma süresinin en az \%70'inin hazırlık için harcanması gerektiğini belirtmiştir. Karatay (2011) hazırlık aşamasının etkili bir yazılı anlatım için önemli olduğunu ifade etmiştir. Doğan (2020) ise hazırlık aşamasının süreç temelli yazmanın ilk ve belki de en önemli aşaması olduğunu belirterek bu aşamanın yazma gelişimi açısından önemli olduğunu ifade etmiştir. 
Hazırlıksız olarak başlanılan işlerde karışıklık ve belirsizliklerin olabileceği gibi hazırlıksız olarak başlanılan yazma süreçlerinde de karmaşa ve belirsizlik meydana gelebilir.

Hazırlık; yazma konusu, amacı, yazı türü ve hedef kitle belirleme çalışmalarının yapıldığı yazma sürecinin ilk aşamasıdır. Aydın (2019)'a göre yazmaya başlamadan önce gerekli hazırıkların yapıldığı bu aşama yazma sürecinin ilk ve en önemli aşamasıdır. Tompkins (2017) bu aşamayı sporcuların maça çıkmadan önce yaptıkları ısınma hareketlerine benzeterek yazma sürecinde harcanan zamanın büyük bir kısmının hazırlığa ayrılması gerektiğini vurgulamıştır. Hazırlık aşamasında konu belirlenmeli, konu sınırlandırılmalı ve yazma amacı belirlenmelidir (Doğan, 2020; Karatay, 2011). $\mathrm{Bu}$ belirlemelerin hazırlık aşamasında yapılması yazma sürecinin ilerleyen aşamalarında ortaya çıkabilecek belirsizliğin ve karmaşanın önüne geçecektir. Ayrıca bu aşamada konu ve amacın belirlenmesi yazarın yazmanın ilerleyen süreçlerine yönelik duyduğu kaygıyı da azaltabilir. Bu aşamada yazılacaklar hakkında düşünme, konu ile ilgili fikir alışverişinde bulunma, konu ile ilgili araştırma ve okuma yapma, konu ile ilgili neler söylenebileceğini belirleme, yazılacak metin türü ve türün özellikleri hakkında bilgi toplama gibi etkinliklerin yapılması ilerleyen yazma süreçlerinin daha başarılı bir biçimde yürütülmesi açısından önemlidir. Aşağıda Karatay (2011) ve Doğan (2020) gibi araştırmacılar tarafından hazırlık aşamasında takip edilmesi önerilen aşamalar tek tek ele alınmıştır.

Konunun belirlenmesi: Hazırlık aşamasında yapılabilecek işlemlerin başında yazma konusunun belirlenmesi gelmektedir (Tompkins, 2017). Yazılı anlatımda başarılı olmanın ölçütlerinden biri iyi konu seçimidir (Karatay, 2011; Kurudayıoğlu ve Karadağ, 2010). Konu seçiminin yazma akıcılığı (Cohen, 2013), yazma performansı (Bonyadi, 2014), fikir üretimi (Hidi ve McLaren, 1991) gibi unsurlar üzerinde etkili olduğu görülmüştür. Konu seçiminde öğrenci ilgi ve isteği mümkün olduğunca göz önünde bulundurulmalıdır. Bu nedenle konu seçiminde öğrencilerin aktif bir biçimde katılım göstermeleri için gerekli ortamın oluşturulması ve öğrencilerin aktif katılıma teşvik edilmesi önemlidir. Tompkins (2017) bu aşamada yazma konusunun öğrencinin kendi tarafından seçilmesinin daha fazla ilgi ve istekli olmalarını sağlayabileceğini belirtmiştir. Ancak Karatay (2011) özellikle yazmaya yeni başlayan ilköğretim çağındaki öğrencilerin konu seçiminde zorlanabildiğini ve bunun da yazmaya karşı olumsuz tutum geliştirilmesine yol açabildiğini belirtmiştir. Bu nedenle Doğan (2020) hazırlık aşamasında öncelikle konu seçimine dikkat edilmesi gerektiğini vurgulayarak konu seçiminde öğrenciye görelik ilkesinin göz önünde bulundurulması gerektiğine değinmiştir. Sonuç olarak konu seçiminde öğrenci ilgi ve isteği göz önünde bulundurulmalıdır. Ancak konu seçiminde zorlanılması hâlinde öğretmenler öğrencilerine gerekli rehberliği ve desteği sağlamalıdır. Seçilen konuların güncel olması, öğrencilerin ilgi alanına girmesi, konunun öğrenci seviyesine uygun olması yazma sürecinin başarılı bir şekilde yürütülebilmesi açısından yararlı olacaktır. Bu nedenle konu seçiminde öğretmenler bu hususları göz önünde bulundurarak öğrencilere rehberlik etmelidir.

Konunun sınırlandırılması: Hazırlık aşamasında konu seçiminden sonra konunun sınırlandırılması başka bir deyişle konunun genel çerçevesinin belirlenmesi gerekmektedir. Bu işlem konunun hangi yönlerine değinilmesi hangi yönlerine değinilmemesi gerektiği hakkında fikir vererek yazma sürecinde yazara yardımcı olacaktır. Karatay (2011) konu sınırlamasının düşüncelerin zenginleştirilmesi ve derinleştirilmesine katkı sağladığını belirtmiştir. Konunun sınırlandırılması yazıda gereksiz konuları girilmesinin ve konu dağınıklığının önüne geçecektir. Bu aşamada öğretmen konunun nasıl sınırlandırılabileceğini uygulamalı olarak göstermeli ve gerekli durumlarda seçilen konuların sınırlandırılabilmesi için öğrencilerine rehberlik yapmalıdır. Doğan (2020) özel konularda konu sınırlarının daha belirgin olduğunu belirterek bu konularda bilgilerin ve düşüncelerin belli bir çerçevede ortaya konduğuna değinmiş ve bu durumun anlatımda dağınıklığı engellediğini ifade etmiştir. Dolayısıyla konunun özelleştirilmesi başka bir deyişle konunun sınırlandırılması yazma sürecinde karmaşanın ve konu dağınıklığının önüne geçilmesi açısından önemlidir.

Yazma amacının belirlenmesi: Bu aşamada yazının amacı belirlenir (Tompkins, 2017). Karatay'a (2011) göre yazarın konuya olaya veya duruma bakış açısı yazma amacını belirlemektedir. Konu sınırlandırılmasının ardından yazma amacının belirlenmesi ileriki süreçler açısından büyük önem taşımaktadır. Raimes (1983) yazı niteliği üzerinde önemli olan bileşenlerden birinin yazma amacı olduğunu belirtir. Yazma amacı yazma sürecini ve yazma sürecinde gerçekleştirilecek uygulamaları bütünüyle etkileyebilir (Tompkins, 2017). Yazma amacı yazara süreç boyunca ne yapması gerektiği, 
nelere önem vererek yazııında yer vermesi gerektiği hakkında fikir verir. Yazma amacı yazının türüne de işaret edecek ve yazma sürecini bütünüyle etkileyecektir. Flower (1988) okuma ve yazmada amaçların ve amaç belirlemenin öneminden bahsetmiştir. Doğan (2020)'a göre yazma amacı belirlendiğinde ortaya koyulan düşünceler ve bilgilerden hangilerinin nasıl kullanılabileceği belirgin bir hâl alamaya başlamaktadır. Nauman, Stirling ve Borthwick (2011) yazıyı nitelikli yapan unsurlar üzerine gerçekleştirdiği araştırmada yazma amacının yazının niteliği bakımından önemine değinmiştir. Bu nedenle yazma sürecinin başında yazma amacının belirlenerek bu amaç doğrultusunda hareket edilmesi, yazma sürecinde karşılaşılabilecek karmaşanın ve belirsizliklerin önüne geçerek daha nitelikli ürün metinlerin oluşturulmasına katkı sunacaktır.

Hedef kitlenin belirlenmesi: Hedef kitle yazarın yazısını kimin için oluşturduğunu ifade eder. Diğer bir deyişle yazının ulaşması hedeflenen kitleyi ifade etmektedir. Yetenekli yazarlar hedef kitlenin ihtiyaçlarının analiz ederek buna göre yazabilir. Okuyucunun ilgi ve ihtiyaçlarının görmezden gelinmesi yazının okuyucuya hitap etmemesi ile sonuçlanacaktır. Bu durum ise yazma eyleminin amacına ulaşmasını engelleyecektir. Flower (2000) yazarın kendisi ile okur arasındaki bilgi, tutum ve ihtiyaçlardan kaynaklı farklılıkları azaltacak bir ortak zemin oluşturması gerektiğini belirtmiştir. Bunun için yazdıklarımızı kimin okuyacağını kesin olarak bilemesek bile yazarken aklımızda bir hedef kitlenin olması önemlidir. Çünkü yazarken nerelere değinilip nelere değinilmeyeceği ve kullanılan dil hedef kitleye göre şekillenecektir. Bu nedenle yazma sürecinin başında hedef kitlenin belirlenerek buna göre hareket edilmesi yazıların hedef kitleye hitap edebilmesi, böylece değer kazanması açısından önemlidir.

Metin türünün belirlenmesi: Metin, doğru sözcüklerin cümle içerisinde doğru kullanılması ve bu cümlelerin bir araya gelmesi sonucunda anlamsal açıdan bir bütünlük oluşturmasıyla ortaya çıkan bir yapıdır (Sarar Kuzu ve Soytürk, 2019). Metin türünün belirlenmesinde en etkili olan unsurların başında yazının amacı gelmektedir. Yazının amacı metnin türünü belirlemede önemli rol oynar. Örneğin amaç geçmişte yaşanmış bir olayı anlatmak ise bunu yapmaya en uygun metin türü muhtemelen öyküleyici metinler olacaktır. Tavşanlı (2018) öğrencilerin tüm metin türlerinde nitelikli ürünler ortaya koyabilmesi için isteksiz davranılan metin türleri ile ilgili eğlenceli yazma etkinlikleri yapılması gerektiğini belirtmiştir. Metin türü yazma sürecinde gerçekleştirilecek adımları da etkileyebilir. Örneğin bilimsel bir makale yazarken takip edilen adımlar ile bir masal yazarken takip edilen adımlar birbirinden farklılık gösterebilir. Bu nedenle yazma sürecinin başında metin türünün belirlenmesi yazara yapılacaklar hakkında yol gösterecektir.

Yukarıda da görüldüğü gibi konunun belirlenmesi ve sınırlandırılması, yazma amacının, hedef kitlenin ve metin türünün belirlenmesi hazırlık aşamasında gerçekleştirilen belli başlı işlemlerdir. Bu işlemler gerçekleştirilirken tartışma, soru cevap, beyin fırtınası, kümeleme gibi öğrenciyi yazma sürecinin içine katarak aktif kılan tekniklerin kullanılması yararlı olacaktır. Mogahed (2013) yazma öncesinde diğer bir deyişle hazırlık aşamasında beyin fırtınası, serbest yazma, listeleme, kümeleme, görüşme, soru cevap gibi aktivitelerin yararlı olacağını belirtmiş ve bu aşamada grafik organize edicilerden, kavram haritalarından, diyagramlardan yararlanılabileceğini ifade etmiştir. Benzer şekilde Karatay (2011) hazırlık aşamasında beyin fırtınası, tartışma, soru cevap, kümeleme gibi tekniklerin kullanılabileceğini belirtmiştir. Bu aşamanın verimli bir şekilde gerçekleştirilmesi ilerleyen süreçlerin zorlanılmadan, sağlıklı bir biçimde yürütülebilmesine katkı sağlayacaktır.

Alanyazın incelendiğinde süreç temelli yazma yaklaşımı benimsenerek gerçekleştirilen yazma eğitiminin yazma başarısı (Tavşanlı, 2019; Bayat, 2014; Dilidüzgün, 2013), yazma tutumu (Tavşanlı, 2019), yazma kaygısı (Bayat, 2014) gibi unsurlar üzerinde etkili olduğu ifade edilmiştir. Bununla birlikte süreç temelli yazma yaklaşımı çerçevesinde hazırlık çalışmalarının önemi araştırmacılar (Balcı, 2017; Doğan, 2020; Karatay, 2011; Mogahed, 2013; Rohman, 1965) tarafından vurgulanmıştır. Ancak süreç temelli yaklaşım anlayışıyla gerçekleştirilen hazırlık çalışmalarının yazma sürecindeki etkilerini ortaya koymaya yönelik yapılmış olan bağımsız bir çalışma olmadığı görülmüştür. Bu çalışmada alanyazındaki bu boşluktan yararlanılarak hazırlık aşamasının yazma sürecindeki etkileri ele alınmış ve böylece hazırlıkların yazma sürecindeki işlevinin katılımcı deneyimlerinden hareketle ortaya konması amaçlanmıştır. 


\section{Araştırmanın Modeli}

\section{Yöntem}

Bu çalışmada Türkçe öğretmeni adaylarının 4+1 PYDM çerçevesinde gerçekleştirdikleri hazırlıklı yazma deneyimlerinden hareketle hazırlığın yazma sürecindeki işlevlerini ortaya çıkarmak amaçlanmıştır. Bu amaç doğrultusunda araştırma nitel araştırma desenlerinden biri olan olgubilim (fenomenoloji) desenine uygun bir biçimde yürütülmüştür. Olgubilim deseni farkında olduğumuz ancak derinlemesine ve ayrıntılı bir anlayışa sahip olmadığımız olgulara odaklanarak yaşantıları ve anlamları ortaya çıkarmaya yöneliktir (Yıldırım ve Şimşek, 2016). Olgubilim bireylerin deneyimleri sonrasında geliştirdikleri algı ve anlamları sorgulayan bir nitel araştırma desenidir (Ersoy, 2017).

\section{Çalışma grubu}

Bu araştırmada çalışma grubu belirlenirken 4+1 PYDM kapsamında hazırlıklı yazma çalışmaları deneyimine sahip olma durumu ölçüt olarak dikkate alınmıştır. Bu nedenle araştırmada 4+1 PYDM kapsamında hazırlıklı yazma çalışmaları yapmış olan otuz Türkçe öğretmeni adayı çalışma grubu olarak seçilmiştir. Dolayısıyla bu araştırmada ölçüt örneklemeye başvurulduğu söylenebilir. Ölçüt örnekleme yönteminde temel anlayış önceden belirlenmiş bir dizi ölçütü karşılayan bütün durumların çalışılmasıdır (Yıldırım ve Şimşek, 2016). Bu araştırmanın amacı 4+1 PYDM çerçevesinde gerçekleştirilen hazırlık çalışmaları hakkındaki deneyimleri ortaya çıkarmak olduğu için çalışma grubunda 4+1 PYDM çerçevesinde hazırlıklı yazma çalışmaları gerçekleştirmiş olma ölçütünü karşılayan katılımcılar yer almıştır.

\section{Veri Toplama Araçları}

Araştırmada veri toplama aracı olarak yarı yapılandırılmış görüşme formu kullanılmıştır. Bu görüşme formu hazırlıklı yazma çalışmaları yapmış olan katılımcıların deneyimlerini ortaya çıkarmayı amaçlayan açık uçlu sorulardan oluşmaktadır. Yarı yapılandırılmış görüşmeler, araştırmacıların bir ilgi alanında hem sabit seçenekli yanıtlar hem de derinlemesine bilgi almalarına olanak tanımaktadır (Büyüköztürk, Kılıç Çakmak, Akgün, Karadeniz ve Demirel, 2016). Araştırmada kullanılan veri toplama aracı olan yarı yapılandırılmış görüşme formunun kapsam geçerliğinin sağlanması amacı ile bu form Türkçe eğitimi alanından üç uzmanın görüşüne sunulmuştur. Alan uzmanlarından alınan geri bildirimler ve yapılan ön görüşmeler sonucunda forma son hâli verilmiştir.

\section{Verilerin Toplanması}

Veri toplama sürecinde amaç hazırlıklı yazma çalışmaları yapan katılımcıların bu çalışmalarının yazma süreçlerindeki işlevlerini kendi deneyimlerinden hareketle ortaya çıkarmak olduğundan veriler yarı yapılandırılmış görüşmeler aracılığı ile toplanmıştır. Türnüklü (2000) yarı yapılandırılmış görüşmelerde araştırmacının önceden planladığı soruları hazırladığını ve görüşmelerin akışına bağlı olarak yan ya da alt sorularla görüşmeleri şekillendirebildiğini belirtmiştir. Araştırmaya başlanmadan önce araştırmaya gönüllü olarak katılmak isteyenlere araştırma hakkında bilgi vermek amacı ile gönüllü bilgilendirme formu hazırlanmıştır. Yarı yapılandırılmış görüşmeler gerçekleştirilmeden önce katılımcılardan onay alınmış ve gönüllülük durumları göz önüne alınarak görüşmeler gerçekleştirilmiştir. Görüşmeler üç haftalık bir süreçte tamamlanmıştır.

\section{Verilerin Analizi}

Elde edilen veriler betimleyici fenomenoloji kullanılarak çözümlenmiştir. Betimleyici fenomenolojide veri analizi genellikle deneyimlerin betimlenmesi üzerine kurgulanmaktadır (Ersoy, 2017). Verilerin analizinde MAXQDA 20 nitel veri analizi programı kullanılmıştır. Veriler iki farklı kodlayıcı tarafından kodlanmıştır. Kodlama sürecinde uyumun sağlanması amacı ile kod kitabı hazırlanmıştır. Süreç sonunda ise iki farklı kodlayıcının yaptığı kodlamalar için kodlayıcılar arası uyum hesaplanmıştır. Kodlayıcılar arası uyum hesaplaması çalışmada güvenirliğin sağlanması amacı ile gerçekleştirildiği için analiz sonuçlarına aşağıda yer alan geçerlik ve güvenirlik başlığı altında yer verilmiştir. 


\section{Geçerlik ve Güvenirlik}

Araştırmada kullanılan veri toplama aracı olan yarı yapılandırılmış görüşme formunun kapsam geçerliğinin sağlanması amacı ile bu form Türkçe eğitimi alanından üç uzmanın görüşüne sunulmuştur. Alan uzmanlarından alınan geri bildirimler ve yapılan ön görüşmeler sonucunda forma son hâli verilmiştir. Formun güvenirliği içinse bu form aracılığı ile altı Türkçe öğretmeni adayı ile görüşme gerçekleştirilmiş, daha sonra adaylardan alınan yanıtların tutarlığı incelenmiştir. Sonuç olarak formun geçerli ve güvenilir bir ölçme aracı olduğu görülmüştür.

Verilerin analizinde güvenirliği sağlanması amacı ile görüşmelerden elde edilen veriler yazılı olarak MAXQDA nitel veri analizi programına aktarılmış ve kodlamalar iki bağımsız kodlayıcı tarafından yapılmıştır. Daha sonra bu iki bağımsız kodlayıcı arasındaki uyum incelenmiştir. Kodlayıcılar arası uyumun hesaplanmasında Miles ve Huberman (1994)'ın formülü kullanılmıştır. Sonuç olarak kodlayıcılar arası uyumun 89 olduğu görülmüştür. Miles, Huberman ve Saldana (2014) kod şemasının boyutuna ve aralığına bağlı olarak kodlayıcılar arası uyumun .85 ile .90 aralığında olması gerektiğini belirtmektedir. Dolayısıyla çalışmada yeterli düzeyde kodlayıcılar arası uyum sağlandığı söylenebilir. Bununla birlikte araştırma verileri sunulurken şeffaflığın sağlanması amacı ile kodlamalar altında yer alan doğrudan katılımcı ifadelerine yer verilmiştir.

\section{Araştırma ve Yayın Etiği}

Bu çalışmada "Yükseköğretim Kurumları Bilimsel Araştırma ve Yayın Etiği Yönergesi" kapsamında uyulması belirtilen tüm kurallara uyulmuştur. Yönergenin ikinci bölümü olan "Bilimsel Araştırma ve Yayın Etiğine Aykırı Eylemler" başlığı altında belirtilen eylemlerden hiçbiri gerçekleştirilmemiştir.

\section{Etik Kurul İzi} Başkanlığı

Kurul adı = Nevşehir Hacı Bektaş Veli Üniversitesi Bilimsel Araştırmalar ve Yayın Etik Kurulu

Karar tarihi $=19.02 .2021$

Belge sayı numarası $=2021.03 .68$

\section{Bulgular}

Bu bölümde yapılan analizler sonucunda elde edilen bulgulara yer verilmiştir. Verilerin analiz edilmesi sonucunda hazırlık aşamasının yazma sürecindeki işlevlerine ilişkin elde edilen kodlar aşağıda sunulmuştur:

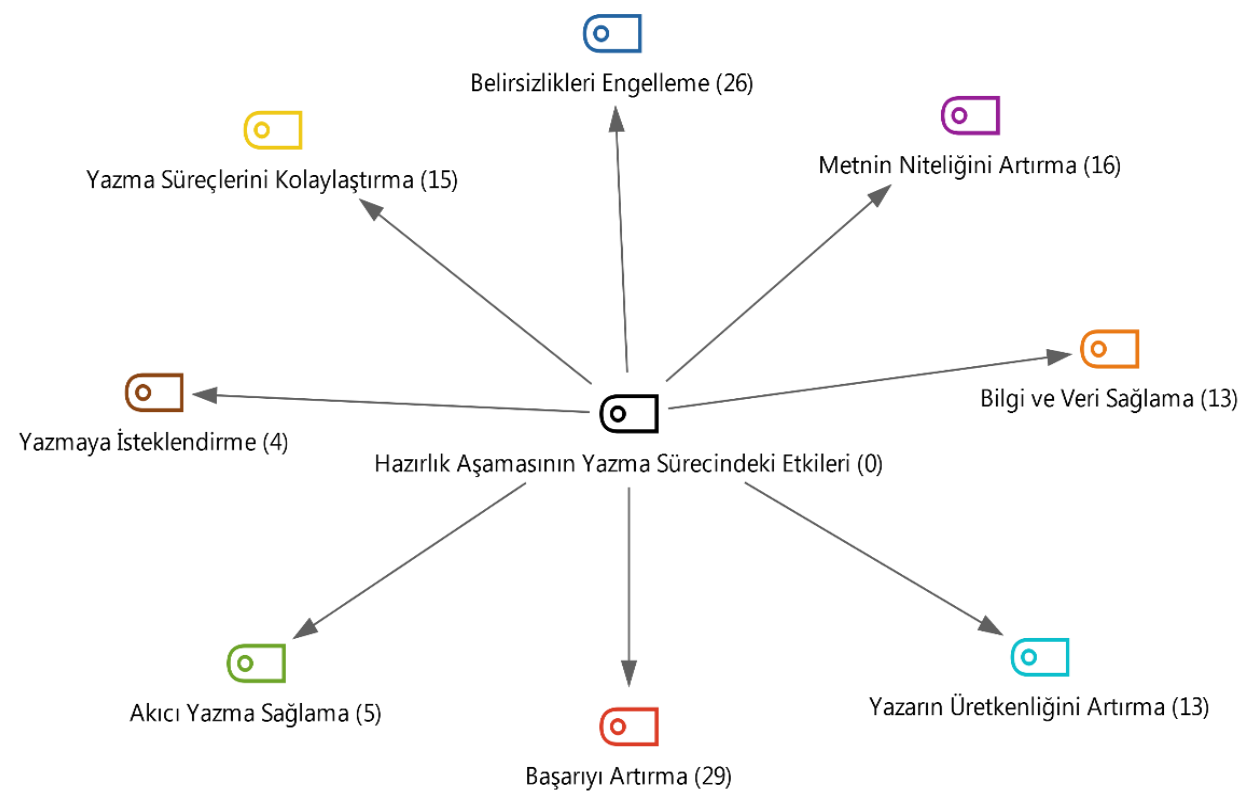

Şekil 1. Hazırlık Aşamasının Yazma Sürecindeki İşlevleri 
Şekil 1'de görüldüğü gibi öğretmen adaylarına göre hazırlık aşamasının yazma sürecindeki işlevleri şunlardır:

a. Belirsizlikleri engelleme: Hazırlık aşamasında metne ve yazma sürecine yönelik kararlar alınmakta, böylece yazma sürecinde yapılacaklara ilişkin belirsizlikler ortadan kalkmaktadır.

b. Metnin niteliğini artırma: Hazırlık aşamasında konuya ilişkin okumaların, araştırmaların ve fikir alışverişlerinin yapılması metnin niteliği üzerinde belirleyici olmaktadır.

c. Bilgi ve veri sağlama: Hazırık aşamasında metnin konusu, türü, amacı hakkında beyin fırtınası, tartışma gibi tekniklerle bilgi alışverişinin yapılması yazma konusu ile ilgili bilgi ve veri sağlamaktadır.

d. Yazarın üretkenliğini artırma: Hazırlık aşamasında yazarın konu ile ilgili bilgi ve veri toplaması yazarın yazma sürecindeki üretkenliğini artırmaktadır.

e. Başarıyı artırma: Hazırlık aşamasında yapılan okumalar, araştırmalar ve fikir alışverişleri yazma başarısını artırabilmektedir.

f. Akıcı yazma sağlama: Hazırlık aşamasında konunun ve yazma amacının belirlenmesi ve bunlarla ilgi bilgi toplanması yazma sürecindeki belirsizlikleri engelleyerek akıcı yazma imkânı sunmaktadır.

g. Yazmaya isteklendirme: Hazırlık aşamasında yazma amacının, konunun ve metin türünün belirlenmesi ve bunlarla ilgili okuma, araştırma ve fikir alışverişlerinin yapılması yazarın kendisini yazmaya hazır hissetmesini ve yazmaya istek duymasını sağlamaktadır.

h. Yazma süreçlerini kolaylaştırma: Hazırlıklar yazma konusu ile ilgili bilgi sağlayarak planlama, düzenleme ve düzeltme gibi yazmanın diğer süreçlerini kolaylaştırmaktadır.

Katılımcılar hazırlık aşamasında metnin konusunu, türünü ve amacını belirlediklerini, konuyla ilgili araştırma ve okuma yaptıklarını, ayrıca arkadaşları ile fikir alışverişinde bulunduklarını ifade etmişlerdir. Bu doğrultuda hazırlık aşamasının yazma sürecinde belirsizlikleri engellediğini, metnin niteliğini artırdığını, konuya ilişkin bilgi ve veri sağladığını dile getirmişlerdir. Ayrıca katılımcılara göre hazırıklar yazarın üretkenliğini ve yazma isteğini artırmaktadır. Benzer şekilde katılımcılara göre hazırlıklar belirsizlikleri gidererek akıcı yazmayı sağlamakta ve yazma süreçlerinin daha kolay bir şekilde tamamlanmasına katkı sunmaktadır. Aşağıda hazırlık aşamasının yazma sürecindeki bu işlevleri ayrıntıları ile birlikte tek tek ele alınmış ve katılımcılardan alınan doğrudan alıntılar ile birlikte sunulmuştur.

Belirsizlikleri engelleme: Katılımcılardan bazıları gerçekleştirilen hazırlık çalışmalarının yazma sürecindeki belirsizliklerin önüne geçtiğini ifade etmişlerdir. Onlara göre hazırlıklar konu ve metin hakkında bilgi vererek belirsizliklerin engellemektedir. Katılımcıların bu koda ilişkin ifadelerinden bazıları şunlardır:

"Ders sürecinde yaptığımız yazmaya hazırlık çalışmaları ile zihnimizde bir plan oluşturuyoruz. Oluşturduğumuz bu plan sayesinde yazacağımız metne nasıl yaklaşacağımızı, cümlelerimizi nasıl oluşturacağımızı, kâğıt düzeninin nasıl olması gerektiğini belirlemiş oluyoruz" (ÖA3).

"Yazmaya yönelik hazırlıklar yazma işini planlı hale getirmemi sağladı öncelikle. Iş̧i ciddiye almayı sağlıyor. Önceden daha gelişigüzel yazabiliyordum aklıma sonradan gelen düşünceleri aktarırken neyi nereye yazacağımı bilemeyip giriş, gelişme ve sonuç kısımlarında karışıklık yaşayabiliyordum" (ÖA8).

"Hazırlık yapmadan doğrudan yazıya başlamak daha içine hangi malzemelerin koyulacağını bilmeden yemek yapmaya başlamak gibidir. Bu nedenle hazırlık yapmamız yararlı oluyor" (ÖA30).

Metnin niteliğini artırma: Bazı katılımcılar yazma öncesinde gerçekleştirilen hazırlıkların metnin niteliği üzerinde etkili olduğunu ifade etmişlerdir. Onlara göre yazmaya hazırlık çalışmaları metnin daha nitelikli ve daha kaliteli hâle gelmesinde ve konu bütünlüğünün sağlanmasında etkili olmaktadır. Katılımcıların bu koda ilişkin ifadelerinden bazıları şunlardır:

"Yazma sürecime baktığımda, şimdiye kadar birçok yazma süreci içerisinde bulundum ve bu süreçlerde hazırlığımı çok detaylı ve düzgün yaptığım yazılarımın diğer yazılarıma göre daha güzel ve etkili olduğunun farkına vardım" (ÖA5). 
"Ben daha önce hazırlık aşamasını yapmıyordum ve yazılarım daha özensiz, daha kısa ve daha kalitesizdi." (ÖA10).

"Yazmaya hazırlık süreci yazı yazmamı kolaylaştırdı. Yazıya hazırlıklı olarak başlamak ise yazımın daha derli toplu olmasını sağladı"(ÖA16).

Bilgi ve veri sağlama: Katılımcılar yazma öncesinde gerçekleştirilen hazırlıkların konuya ve metne ilişkin bilgi ve veri sağlama açısından etkili olduğunu ifade etmişlerdir. Aşağıda yer alan ifadeler hazırlık çalışmalarının yazara metin için bilgi ve veri toplama imkânı sağladığını göstermektedir. Katılımcıların bu ifadelerinden bazıları şunlardır:

"Ders sürecinde yaptığımız yazmaya hazırlık çalışmalarının yazma sürecime olumlu bir şekilde etki ettiğini düşünmekteyim. Hazırık aşaması, benim için bir bakıma kişsisel deneyimlerimi ortaya koyabildiğim, farklı kişilerin düşüncelerinden yararlanabildiğim, bunlara ek olarak anlatmak isteğim konuyla ilgili bilgi topladığım oldukça faydalı ve elverişli bir süreçti” (ÖA24).

"Bir yazıya başlamak için gerekli olanların en başında veri gelmektedir. Yazmaya hazırlık çalışmaları yazı için gerekli olan veriyi bize sunmaktadır" (ÖA25).

"Yaptığım hazırlık çalışmaları yazı yazmaya hazır hale gelmemi, metin yazabilecek bilgiye sahip olmamı daha sağlam ve nitelikli metinler oluşturmamı sağladı" (ÖA30).

Yazarın üretkenliğini artırma: Katıımcılardan bazıları hazırlığın üretkenlik üzerinde etkili olduğunu bildirmişlerdir. Diğer bir deyişle katılımcılara göre yapılan hazırlıklar yazma sürecinde üretken olunabilmesi açısından etkilidir. Katılımcıların bu koda ilişkin görüşlerinden bazıları şöyledir:

"Ben daha önce hazırlık aşamasını yapmıyordum ve yazılarım daha özensiz, daha kısa ve daha kalitesizdi. Yazmaya hazırlık olmadığında yazı yazmam zorlaşıyor" (ÖA10).

"Hazırlıklar sayesinde artık daha çok yazabiliyor ve daha çok üretebiliyorum. Ayrıca yazı yazarken daha pratik düşünme fırsatları oluşturabiliyorum" (ÖA20).

"Yaptığım hazırlık çalışmaları yazı yazmaya hazır hale gelmemi, metin yazabilecek bilgiye sahip olmamı daha sağlam ve nitelikli metinler oluşturmamı sağladı. Ayrıca hacim olarak daha hacimli ürünler ortaya koymama yardıma oldu. Daha fazla fikir üretebiliyor ve daha fazla yazabiliyorum" (ÖA30).

Başarıyı artırma: Katılımcılardan bazıları hazırlık çalışmalarının yazma başarılarını artırdığı yönünde görüş bildirmişlerdir. Aşağıda yer alan katııımcı ifadelerine göre hazırlık çalışmaları yazmaya hazırbulunuşluk sağlamakta böylece yazma başarısını artırmaktadır. Katılımların bu görüşlerine ilişkin ifadelerinden bazıları şunlardır:

"Hazırlık çalışması, yazma sürecinde planlı bir şekilde hareket ederek yazma sürecindeki aşamaları doğru bir şekilde gerçekleştirmemde etkili oldu" (ÖA1).

"Yaptığımız bu hazırlık çalışmalarının beni yazma sürecine daha hazır hale getirdiğini düşünüyorum. Beni yazma sürecine daha fazla güdülediğini ve böylece ortaya daha iyi yazılar çıkarmamı sağladığını fark ediyorum. Konfüçyüs'ün de dediği gibi başarı hazırlığa bağlıdır ve hazırlık olmadan başarısızlıkların ortaya çıkması kesindir" (ÖA29).

Akıcı yazma sağlama: Katılımcılar hazırlıkların akıcı yazmanın sağlanması açısından önemli olduğunu dile getirmişlerdir. Buna göre katılımcılar hazırlıkların akıcı yazma üzerinde etkili olduğunu belirtmektedir. Katılımcıların bu duruma ilişkin ifadelerinden bazıları şunlardır:

"Yazmaya hazırlık olmadığı zaman, yazmadan önce epey bir düşünmem ve kafa yormam gerekiyor. Ancak hazırlıklarla daha hızlı ve doğru yazabildim" (ÖA10).

"Yazmaya hazırlık çalışmaları yaparak yazma sürecimin daha hızlı ve daha etkili olduğunu gördüm" (ÖA16).

"Neyi, nerede yazacağımı daha iyi bildiğim için bocalamadan ve daha anlamlı yazılar oluşturabildim" (ÖA17). 
Yazmaya isteklendirme: Bazı katılımcılar hazırlıkların kendilerini yazmaya isteklendirme noktasında etkili olduğunu belirtmişlerdir. Onlara göre hazırlık çalışmaları onların yazmaya hazırbulunuşluğunu artırarak yazmaya isteklendirmektedir. Katılımcıların bu duruma ilişkin görüşlerinden bazıları şunlardır:

"Hazırlık aşamasında amacımı belirlemem yazma sürecimi olumlu yönde etkiledi çünkü amacım beni yazı yazmaya daha da motive etti" (ÖA16).

"Hazırlıkların beni yazma sürecine daha fazla güdülediğini ve böylece ortaya daha iyi yazılar çıkarmamı sağladığını fark ediyorum" (ÖA29).

"Hazırlıkların bizi yazmaya karşı daha istekli ve bilinçli hale getirdiğini söyleyebilirim" (ÖA30).

Yazma süreçlerini kolaylaştırma: Katılımcılar hazırlıkların yazma süreçlerini kolaylaştırdığını ifade etmişlerdir. Onlara göre hazırlıklar yazma sürecinde konuya ve metne ilişkin bilgi ve veri sağlayarak yazma süreçlerinin kolay bir biçimde tamamlanması açısından önemlidir. Katılımcıların bu duruma ilişkin ifadelerinden bazıları şunlardır:

"Yazmaya hazırlık çalışmaları bizi yazıya hazırlar. Yazmaya başlamadan önce konu ve tür hakkında tartışmak yazma esnasında bana kolaylıklar sağlıyor" (ÖA10).

"Yazacağım konuya karar vermek, bu konuyla ilgili bilgiler toplamak, konuya ilişkin türü belirlemek yazma sürecimi kolaylaştırdı" (ÖA11).

"Hazırlık çalışmalarının yazma sürecini daha planlı ve kolay hale getirdiğine inanıyorum. Metne hâkimiyeti sağlıyor. Metnin yazılış amacına ışık tutarak yol gösterici oluyor" (ÖA15).

\section{Tartışma ve Sonuç}

Araştırmada elde edilen bulgular gerçekleştirilen hazırlık çalışmalarının yazar, metin ve yazma süreci üzerinde olumlu etkilerinin olduğunu göstermiştir. Bulgulara göre hazırlık bir başka deyişle ön yazma çalışmaları yazma sürecini olumlu etkilemekte böylece daha nitelikli yazılı anlatım ürünlerinin ortaya çıkmasını sağlamaktadır. Mahnam ve Nejadansari (2012) gerçekleştirdikleri araştırmada yazma öncesi etkinliklerin yazma başarısı üzerinde etkili olduğu sonucuna ulaşmıştır. Benzer şekilde Zaid (2011) web tabanlı ön yazma aktivitelerinin yazma performansı üzerinde etkili olduğu sonucuna ulaşmıştır. Bununla birlikte yazma öncesinde gerçekleştirilen hazırlıkların yazma performansı üzerinde etkili olduğu ifade edilmiştir (Baaijen, Galbraith ve Glopper, 2014). Bu bulgular araştırmada elde edilen bulguları destekler niteliktedir. Tüm bunlar yazma öncesinde gerçekleştirilen yazmaya hazırlık çalışmalarının hem yazma sürecine hem de ürün metne olumlu yansımalarının olduğunu göstermektedir.

Araştırma bulguları hazırık sürecinin ortaya konan ürün metin üzerindeki olumlu etkilerini göstermiştir. Buna göre hazırlık aşaması yazara metin için bilgi ve veri toplama imkânı sağlamakta böylece metnin niteliği üzerinde belirleyici olmaktadır. Başka bir deyişle hazırlık aşamasında toplanan bilgi ve veriler yazarın daha nitelikli fikirler ortaya koymasına böylelikle nitelikli metinler oluşturmasına yardımcı olmaktadır. Mogahed (2013) yazma öncesi aktivitelerin fikir üretilmesine katkı sunduğunu ve bu açıdan yazmanın önemli bir süreci olduğunu ifade etmiştir. Crossley, Muldner ve McNamara (2016) ise fikir üretiminin yazma teorilerinin önemli bir bileşeni olduğunu ve yaratıcılıkla ilişkili olduğunu belirtmiştir. Yazma öncesinde gerçekleştirilen hazırıkların ortaya konan yazılı ürünler üzerinde etkili olduğu ifade edilmiştir (Brodney, Reeves ve Kazelskis, 1999). Tüm bunlar hazırlıkların yazma sürecindeki fikir üretimi ve bu süreçteki yaratıcılık açısından önemli olduğunu göstermektedir.

Bulgular hazırlık sürecinin yazarı da etkilediğini göstermiştir. Buna göre hazırlıklar yazarın yazma başarııını artırmakta, yazmaya daha çok istek duymasını sağlamakta ve yazma sürecindeki üretkenliğini artırabilmektedir. Hazırlıklar metnin konusunun, türünün ve amacının belirlendiği ve bunlarla ilgili bilgilerin toplandığı bir süreçtir. Dolayısıyla bu süreç yazarın metnin konusu, türü ve amacı hakkında daha çok bilgi sahibi olmasına yardımcı olmaktadır. Bu durum ise yazma isteğini artırabileceği gibi yazarın fikir üretimini de kolaylaştırabilmektedir. Aydın (2019) sağlıklı bir hazırlık sürecinin yazma başarısını artıracağını ifade etmiştir. Zheng ve Dai (2012) yazma öncesi etkinliklerin söylemek istenilenlerin belirlenmesine ve fikir üretilmesine katkı sunabileceğini ifade etmektedir. 
Tüm bunlar değerlendirildiğinde hazırlık sürecinin fikir üretimi ve yazma başarısı açısından önemli olduğu söylenebilir. Dolayısıyla yazma öncesi gerçekleştirilen hazırlık sürecinin yazarın yazmaya hazırbulunuşluğu için önemli olduğu ve daha iyi yazma performansı göstermesine katkı sunduğu söylenebilir.

Bulgular hazırlık sürecinin yazmanın diğer süreçleri açısından da önemli olduğunu göstermiştir. Nitekim bulgulara göre hazırlıklar yazma sürecine yönelik belirsizlikleri engellemekte böylelikle daha kolay ve akıcı bir yazma sürecinin gerçekleştirilmesinde rol oynamaktadır. Yapılan hazırıklar metnin konusunun, amacının, türünün ve hedef kitlesinin belirlenmesini sağlamaktadır. Bu durum ise yazma sürecinin daha akıcı bir biçimde sürdürülmesine olanak tanımaktadır. Dickinson (2014) konu seçiminin yazma akıcılığı üzerinde etkili olduğunu görmüştür. Bu bulgu araştırmada elde edilen bulguları destekler niteliktedir. Çünkü hazırlık aşaması konu seçiminin netleştirildiği aşamadır. Zheng ve Dai (2012) yazma öncesi etkinliklerin özgür düşünce üretimini teşvik edebileceğini belirtmiştir. Özgür düşünce üretimi ise akıcı yazmayı beraberinde getirecektir. Doğan (2020) gerçekleştirdiği çalışmada hazırlığın bütün yönleri ile ele alındığında bunun, yazma sürecinin diğer aşamalarını da olumlu yönde etkileyeceğini ve süreci hızlandıracağını ifade etmiştir. Bu yönü ile Doğan tarafından dile getirilenlerle bu çalışmada elde edilen bulguların uyumlu olduğu söylenebilir. Nitekim bu çalışmada elde edilen bulgular hazırlıkların yazmanın diğer süreçlerini kolaylaştırabildiğini göstermektedir. Ayrıca bulgular hazırlıkların akıcı bir şekilde yazılarak daha kısa sürede yazının sonlandırımasına da katkı sunabileceğini göstermektedir. Erbilen'in (2020) gerçekleştirdiği çalışmanın bulguları yazma öncesi etkinliklerin yazma başarısı ve yazma isteği üzerinde olumlu etkinlerinin olduğunu göstermiştir. Benzer şekilde Mahnam ve Nejadansari (2012) tarafından gerçekleştirilen çalışmanın bulguları da yazma öncesi etkinliklerin yazma başarısı üzerinde önemli bir etkisinin olduğunu göstermiştir. Bu çalışmada da bulgular yazma öncesinde yapılan hazırlıkların yazarın üretkenliğini ve başarısını artırdığını göstermiştir. Bu yönü ile Doğan, Erbilen, Mahnam ve Nejadansari tarafından gerçekleştirilen araştırmalar ile bu araştırmanın bulgularının birbirini desteklediği söylenebilir. Bununla birlikte Murray (1982) ve Tompkins (2017) hazırlıkların yazmanın başarılı bir şekilde gerçekleştirilebilmesi için önemli olduğunu, bunun için hazırlık yapabilmeleri amacıyla öğrencilere yeterli zamanın verilmesi gerektiğini belirtmişlerdir. Bu araştırmada da bulgular hazırlıkların yazma başarımı ve ürün metin üzerinde olumlu etkilerinin olduğunu göstermektedir. Tüm bunlar göz önüne alındığında gerçekleştirilen hazırlıkların yazma başarımı açısından önemli olduğu söylenebilir.

Bu araştırmada elde edilen bulgulardan hareketle hazırlık sürecinin ürün metin, öğrenci ve yazma başarımı üzerinde birçok olumlu etkisi olduğu sonucuna ulaşılmıştır. Araştırmada elde edilen bulgulardan hareketle hazırlıkların başlıca işlevlerinin şunlar olduğu sonucuna ulaşılmıştır:

1. Hazırlık süreci metnin amacının, konusunun ve türünün belirlendiği ve buna göre bilgi edinme yollarına başvurulduğu süreçtir. Dolayısıyla bu süreç metne ve yazmanın diğer süreçlerine yönelik belirsizliklerin giderilmesinde etkili olabilmektedir. Metne ve sürece yönelik belirsizliklerin giderilmesi ise yazma başarımını olumlu etkilemekte ve daha nitelikli metinlerin ortaya çıkmasına zemin hazırlamaktadır.

2. Hazırlık aşamasında yazının konusu ve türü belirlendikten sonra konu ve tür ile ilgili bilgi edinme yollarına başvurulmaktadır. Bu durum öğrencinin konuyla ve türle ilgili bilgisini artırmakta, ona yazarken kullanabileceği veriler sağlamaktadır. Böylece hazırlıklar fikir üretimini ve yazma başarımını olumlu etkileyebilmektedir. Fikir üretiminin artması ise akıcı yazmayı ve yazma başarımını beraberinde getirmektedir.

3. Hazırıklar öğrencinin konu ile ilgili bilgisini artırmaktadır. Bu durum yazarın yazmaya olan isteğini de artırabilmektedir. Hazırlık aşamasında yazar konu bilgisinin artması ile birlikte taslak oluşturma, geliştirme gibi diğer süreçleri daha kolay bir şekilde yürütebilmekte, bu süreçlerde daha iyi başarım gösterebilmektedir.

Bu araştırma yazma süreçlerinden ilki olarak benimsenen hazırlık aşamasının üretilen metnin ve yazma sürecinin niteliği açısından önemini ortaya koymaktadır. Araştırma sonuçlarına göre gerçekleştirilen hazırlık çalışmaları yazarın konu ile ilgili bilgi ve veri toplamasını sağlayarak yazma sürecini daha başarılı bir şekilde yönetmesini mümkün kılmaktadır. Ayrıca hazırlıklar yazarın hem 
psikolojik hem de fiziksel olarak yazmaya hazır olmasını sağlamaktadır. Hazırlık sürecinin yazar ve süreç üzerindeki bu yansımaları ortaya konan ürün metin üzerinde de belirleyici olmaktadır. Hazırlıklar sayesinde yazar metnin konusu ile ilgili yeterince bilgi ve veri toplama imkânı bulmakta böylece daha nitelikli metinler ortaya çıkarabilmektedir. Elde edilen bu sonuçlardan hareketle şu önerilerde bulunulabilir:

1. Her şeyden önce yazmanın bir süreç olduğu ve bu sürecin ortaya konan ürün metin üzerinde belirleyici olduğu unutulmamalıdır. Nitekim bu araştırmada yazma süreçlerinden biri olarak ele alınan hazırlık aşamasının yazar, metin ve yazma süreci üzerinde olumlu etkileri olduğu görülmüştür. Bu nedenle öğretmenler yazma süreçleri ve bu süreçlerin nasıl yönetilebileceği hakkında öğrencilerine bilgi ve beceri kazandırımalıdır.

2. Öğretmenler yazma öncesinde hazırlık çalışmaları yapma konusunda öğrencilerine örnek olmalı ve bu konuda onlara alışkanlık kazandırmalıdır. Nitekim bu çalışmanın sonuçları hazırlıkların yazma başarımı ve ortaya konan ürün metin açısından önemli olduğunu göstermektedir.

3. Alanyazında beyin fırtınası, tartışma, soru cevap gibi tekniklerin hazırlık aşamasında kullanılabileceği belirtilmektedir. Hazırlık aşamasında kullanılan bu gibi yöntem ve tekniklerden farklı olarak ne gibi yöntem ve tekniklerin, uygulamaların, etkinliklerin ortaya konabileceği ve bunların etkililiğinin araştırılması alana katkı sağlayacaktır.

\section{Araştırma ve Yayın Etiği}

Bu çalışmada "Yükseköğretim Kurumları Bilimsel Araştırma ve Yayın Etiği Yönergesi" kapsamında uyulması belirtilen tüm kurallara uyulmuştur. Yönergenin ikinci bölümü olan "Bilimsel Araştırma ve Yayın Etiğine Aykırı Eylemler" başlığı altında belirtilen eylemlerden hiçbiri gerçekleştirilmemiştir.

\section{Etik Kurul İni} Başkanlığı

Kurul adı = Nevşehir Hacı Bektaş Veli Üniversitesi Bilimsel Araştırmalar ve Yayın Etik Kurulu

Karar tarihi $=19.02 .2021$

Belge sayı numarası $=2021.03 .68$

\section{Yazarların Katkı Oranı}

Araştırmanın birinci yazarının katkı oranı \%50, ikinci yazarının katkı oranı \%50'dir.

\section{Çıkar Çatışması}

Araştırmada taraflar arasında herhangi bir çıkar çatışması bulunmamaktadır.

\section{Kaynaklar}

Arıcı, A. F. ve Ungan, S. (2015). Yazılı anlatım el kitabı. Pegem Akademi.

Aydın, G. (2019). Yazma eğitimi ile ilgili temel kavramlar. İçinde H. Karatay (Ed.), Dil eğitiminin temel kavramları (ss. 73-99). Ankara: Pegem Akademi.

Baaijen, V. M., Galbraith, D., \& de Glopper, K. (2014). Effects of writing beliefs and planning on writing performance. Learning and Instruction, 33, 81-91.

http://dx.doi.org/10.1016/j.learninstruc.2014.04.001

Balcı, O. (2017). 4+1 planlı yazma değerlendirme modelinin 6. sını öğrencilerinin yazma becerilerini ve yazmaya karşı tutumlarını geliştirmeye etkisi (Yayımlanmamış yüksek lisans tezi). Bolu Abant İzzet Baysal Üniversitesi, Bolu.

Bayat, N. (2014). The effect of the process writing approach on writing success and anxiety. Educational Sciences: Theory and Practice, 14(3), 1133-1141. https://doi.org/10,12738/estp.2014.3.1720

Bonyadi, A. (2014). The effect of topic selection on EFL students' writing performance. Sage Open, 4(3). https://doi.org/2158244014547176 
Brodney, B., Reeves, C., \& Kazelskis, R. (1999). Selected prewriting treatments: Effects on expository compositions written by fifth-grade students. The Journal of Experimental Education, 68(1), 5-20. https://doi.org/10.1080/00220979909598491

Büyüköztürk Ş., Kiliç Çakmak E., Akgün O. E., Karadeniz Ş. ve Demirel F. (2016). Bilimsel araştırma yöntemleri [Scientific research methods]. Ankara: Pegem Akademi.

Cohen, J. (2013). The impact of topic selection on writing fluency: Making a case for freedom. Journal of NELTA, 18(1-2), 31-40. https://www.nelta.org.np/uploads/upload/c3FUNk.pdf

Crossley, S. A., Muldner, K., \& McNamara, D. S. (2016). Idea generation in student writing: Computational assessments and links to successful writing. Written Communication, 33(3), 328-354. https://doi.org/10.1177/0741088316650178

Dickinson, P. (2014). The effect of topic-selection control on EFL writing fluency. Journal of Niigata University of International and Information Studies, 17, 15-25. https://core.ac.uk/download/pdf/229976052.pdf

Dilidüzgün, S. (2013). The effect of process writing activities on the writing skills of prospective Turkish teachers. Eurasian Journal of Educational Research, 52, 189-210. https://eric.ed.gov/?id=EJ1060398

Doğan, Y. (2020). Süreç temelli yazma eğitiminin bir boyutu olarak "hazırlık". Ana Dili Eğitimi Dergisi, 8(2), 326- 342. https://doi.org/10.16916/aded.677716

Emig, J. (1971). The composing process of twelfth graders. Urbana, IL: National Council of Teachers of English. https://eric.ed.gov/?id=ED058205

Erbilen, M. (2020). Yazma öncesi etkinliklerinin yazma motivasyonuna ve yazma başarısına etkisi (Yayımlanmamış Doktora Tezi). Hatay Mustafa Kemal Üniversitesi. Hatay.

Ersoy, A. F. (2017). Fenomenoloji. İçinde A. Saban ve A. Ersoy (Edt.). Eğitimde nitel araştırmalar desenleri, (ss. 81-138). Anı Yayıncılık.

Flower, L. (1988). The construction of purpose in writing and reading. College English, 50(5), 528-550. https://eric.ed.gov/?id=ED298493

Flower, L. (2000). Writing for an audience. In P. Eschholz, A. Rosa, \& V. Clark (Eds.), Language awareness: Readings for college writers (pp. 139-141). (8a ed.). Boston.

Flower, L., \& Hayes, J. R. (1981). A cognitive process theory of writing. College Composition and Communication, 32(4), 365-387. https://www.jstor.org/stable/356600

Graham, S. (2006). Writing. In P. Alexander \& P. Winne (Eds.), Handbook of educational psychology (pp. 457-478). Mahwah, NJ: Erlbaum.

Graham, S., Gillespie, A., \& McKeown, D. (2012). Writing: Importance, development, and instruction. Reading and Writing, 26(1), 1-15. https://doi.org/10.1007/s11145-012-9395-2

Hidi, S. E., \& McLaren, J. A. (1991). Motivational factors and writing: The role of topic interestingness. European Journal of Psychology of Education, 6(2), 187-197. https://www.jstor.org/stable/23423405?seq=1\#metadata_info_tab_contents

Karatay, H. (2011). Süreç temelli yazma modelleri: Planlı yazma ve değerlendirme. İçinde M. Özbay (Ed.), Yazma eğitimi (ss. 21-43). Ankara: Pegem Akademi.

Kurudayıoğlu, M. ve Karadağ, Ö. (2010). İlköğretim Öğrencilerinin Yazılı Anlatımlarının Konu Seçimleri Açısından İncelenmesi. Mustafa Kemal Üniversitesi Sosyal Bilimler Enstitüsü Dergisi, 7(13), 192-207. https://dergipark.org.tr/en/pub/mkusbed/issue/19571/208612

Mahnam, L., \& Nejadansari, D. (2012). The effects of different pre-writing strategies on Iranian EFL writing achievement. International Education Studies, 5(1), 154-160. https://doi.org/10.5539/ies.v5n1p154

Miles, M. B., \& Huberman, A. M. (1994). Qualitative data analysis: An expanded sourcebook (2nd ed.). Thousand Oaks, CA: Sage.

Miles, M.B., Huberman, A.M., \& Saldana, J. (2014). Qualitative data analysis: A methods sourcebook (3rd ed.). Los Angeles: Sage.

Mogahed, M. M. (2013). Planning out pre-writing activities. International Journal of English and Literature, 4(3), 60-68. https://doi.org/10.5897/IJEL12.120 
Murray, D. M. (1972). Teach writing as a process not product. The Leaflet, 71(3), 11-14. https://files.eric.ed.gov/fulltext/ED402614.pdf\#page=18

Murray, D. M. (1982). Learning by teaching: Selected articles on writing and teaching. NJ: Boynton/ Cook.

Nabhan, S. (2019). Bringing multiliteracies into process writing approach in ELT classroom: Implementation and reflection. EduLite: Journal of English Education, Literature and Culture, 4(2), 156-170. http://dx.doi.org/10.30659/e.4.2.156-170

Nauman, A. D., Stirling, T., \& Borthwick, A. (2011). What makes writing good? An essential question for teachers. The Reading Teacher, 64(5), 318-328. https://doi.org/10.1598/RT.64.5.2

Raimes, A. (1983) Techniques in Teaching Writing. Oxford: Oxford University Press.

Rohman, D. G. (1965). Pre-writing the stage of discovery in the writing process. College Composition and Communication, 16(2), 106-112. https://www.jstor.org/stable/354885

Sarar Kuzu, T. ve Soytürk, E. (2019). Ortaokul kompozisyon yazma çalışmalarının metindilbilimin metin üretim evreleri açısından değerlendirilmesi. Uluslararası Çocuk Edebiyatı ve Eğitim Araştırmaları Dergisi, 3(1), 12-29. https://dergipark.org.tr/en/pub/chedar/issue/45464/535651

Seow, A. (2002). The Writing Process and Process Writing. In Jack C. Richards, \& Willy A. Renandya, (Eds.), Methodology in Language Teaching: An Anthology of Current practice. (p. 315-320). New York: Cambridge University Press.

Tavşanlı, Ö. F. (2018). İlkokul öğrencileri ne yazar?: İlkokul öğrencilerinin yazılı anlatımlarında metin türü, konu ve içerik tercihlerinin incelenmesi. Ana Dili Eğitimi Dergisi,6(1), 32-47. https://www.anadiliegitimi.com/tr/download/article-file/414359

Tavşanlı, Ö. F. (2019). Süreç temelli yazma modüler programının ilkokul 2. sınıf öğrencilerinin yazmaya ilişkin tutum, yazılı anlatım becerisi ve yazar kimliği üzerine etkisi (Yayımlanmamış doktora tezi). Bursa Uludağ Üniversitesi, Bursa.

Tompkins, G. E. (2005). Language Arts Patterns of Practise (6. edition). New Jersey: Pearson Publishing.

Tompkins, G. E. (2017). Literacy for the 21st century: A balanced approach (7. edition). NJ: Pearson Education.

Türnüklü, A. (2000). Eğitimbilim araştırmalarında etkin olarak kullanılabilecek nitel biraraştırma tekniği: Görüşme. Kuram ve Uygulamada Eğitim Yönetimi, 24(24), 543-559. https://dergipark.org.tr/en/download/article-file/108517

Yıldırım, A. ve Şimşek, H. (2016). Sosyal bilimlerde nitel araştırma yöntemleri (10. bs.). Ankara: Seçkin Yayıncılık.

Zaid, M. A. (2011). Effects of web-based pre-writing activities on college EFL students' writing performance and their writing apprehension. Journal of King Saud University-Languages and Translation, 23(2), 77-85. https://doi.org/10.1016/j.jksult.2011.04.003

Zheng, S., \& Dai, W. (2012). Studies and Suggestions on Prewriting Activities. Higher Education Studies, 2(1), 79-87. http://dx.doi.org/10.5539/hes.v2n1p79

\section{Introduction}

\section{Extended Abstract}

Writing is a goal-directed and self-sustaining cognitive activity that requires skillful management of the elements that affect the writing process. It is a powerful way to influence others, and a powerful tool (Graham, Gillespie \& McKeown, 2012). Graham (2006) stated that writing is an action performed for different purposes and defined writing as a versatile tool that could be used to achieve different purposes. Writing is an activity carried out for many different purposes such as giving information, expressing feelings and thoughts, and having fun. For this reason, writing skill has an important place in school and business life, as it is in every field of human life today.

The processes employed in pre-writing, including planning are adopted in almost all studies that adopt a process-based approach to writing. These processes, carried out before writing, have an impact on writing performance (Baaijen, Galbraith, \& de Glopper, 2014) and on the written products 
(Brodney, Reeves, \& Kazelskis, 1999). Mogahed (2013) stated that especially young writers had difficulties in starting and writing and that pre-writing activities were thus important. Murray (1982) stated that at least $70 \%$ of writing time should be spent on pre-writing activities. Karatay (2011) stated that the pre-writing stage was important for written expression to be effective. Doğan (2020), on the other hand, stated that the pre-writing stage was the first and perhaps the most important stage in process writing and that this stage was important for the development of writing. Confusion and uncertainty could result in writing efforts that started without preparation.

Determining and limiting the topic, determining the purpose, targeting the audience, and choosing the text type are the main operations carried out during the pre-writing phase. While performing these processes, it will be useful to use techniques such as discussion, question-answer, brainstorming, and clustering, each of which makes student writers active by involving them in the writing process. Mogahed (2013) stated that activities such as brainstorming, freewriting, listing, clustering, interviewing, and question and answer would be beneficial during the pre-writing phase, and stated that graphic organizers, concept maps, and diagrams could be used at this stage. Similarly, Karatay (2011) stated that techniques such as brainstorming, discussion, question and answer, and clustering could be used in the pre-writing phase. Performing this stage efficiently will contribute to the successful execution of the subsequent processes.

It is stated that teaching writing, adopting a process-based writing approach, is effective on factors such as writing success (Tavşanlı, 2019; Bayat; 2014; Dilidüzgün, 2013), writing attitude (Tavşanlı, 2019), and writing anxiety (Bayat; 2014). In addition, the importance of pre-writing in process writing was emphasized by researchers (Karatay, 2011; Doğan, 2020; Mogahed, 2013; Rohman, 1965). However, it is seen that there is no independent study that aims to reveal the effects of process-based pre-writing on the writing process. To fill this gap in the literature, this study focused on the effects of the pre-writing phase in the writing process to reveal the functions of prewriting in the writing process.

\section{Method}

The study was carried out using the phenomenology methodology and is thus qualitative by design. The phenomenology design focuses on facts that we are aware of but do not have a deep and detailed understanding of (Yıldırım \& Şimşek, 2016). In determining the study group, having experience in pre-writing activities was the criterion. Thirty Turkish teacher candidates who had done pre-writing activities were selected based on that criterion. A semi-structured interview form was used as a data collection tool in the research. To provide content validity, a semi-structured interview form, used as the data collection tool, was sent to three experts in the field of Turkish language teaching. The interview form was modified and finalized in accordance with the feedback from the field experts and the pilot interviews. The data were collected through semi-structured interviews. The data were analyzed using descriptive phenomenology. Data analysis in descriptive phenomenology is generally built on the description of experiences (Ersoy, 2017). The MAXQDA software was used in the analysis of the data. During the data analysis, codes were formed by two independent researchers. A codebook was prepared to ensure reliability in the coding process. At the end of the process, the inter-rater reliability was calculated by using the formula suggested by Miles and Huberman (1994). The inter-rater reliability was .89.

\section{Results and Discussion}

The findings showed that the pre-writing phase was as important as the other processes in writing. The results showed that pre-writing activities prevented ambiguities regarding the writing process and thus, made the writing process easier and more fluent. As the pre-writing stage helps writers determine the writing purpose, text type, and target audience, it allows the writing process to continue more fluently. Dickinson (2014) found that topic selection had an effect on writing fluency. As stated, in this study topic selection was made in the pre-writing stage. Zheng and Dai (2012) stated that pre-writing activities could encourage the production of free thought. Free thought production leads to fluent writing. Doğan (2020) stated that when all aspects of pre-writing are 
covered thoroughly, they positively affect the other stages of the writing process and accelerate it. It may be stated that the findings of this study are in line with those expressed by Doğan. The findings showed that pre-writing could facilitate other processes of writing, accelerate the writing process, and contribute to the completion of writing in a shorter time. Erbilen (2020) showed that pre-writing activities had positive effects on writing success and students' willingness to write. Similarly, the findings of the study conducted by Mahnam and Nejadansari (2012) showed that pre-writing activities had a significant effect on writing success. In this study, the findings showed that the preparatory activities made before writing increased the productivity and success of the writer. Murray (1982) and Tompkins (2017) stated that pre-writing was important for successful writing and that students should be given sufficient time for pre-writing. The findings of this study showed that pre-writing had positive effects on writing performance and the product text. Thus, it may be argued that as the pre-writing stage had positive effects on the other processes of writing, it was important in terms of the overall success in writing.

Based on the findings of this study, it was concluded that the pre-writing stage had many positive effects on the produced text, the student writer, and writing success. This study reveals the importance of the pre-writing phase in terms of the quality of the produced text and the writing process. According to the results, pre-writing activities enable the author to collect information and data on the subject and manage the writing process more successfully. In addition, pre-writing activities ensure that the writer becomes ready to write both psychologically and physically. These effects of the pre-writing stage on the writer and the process are also decisive on the product text. Thanks to pre-writing, writers find the opportunity to collect enough information and data about the subject of the text, and more qualified texts are produced. In sum, the results of this study show that the pre-writing stage is important in terms of writing performance. 